\title{
siete claves éticas PARA EMPRENDEDORES
}

Jerónimo García Ugarte

Profesor de filosofía y psicología

1202ugarte@gmail.com

¿SE PUede EMPRENDER Sin ÉticA?

í. Y solamente hace falta un breve recorrido por nuestra actual realidad política, social y económica para reafirmarme en el "si", e incluso me atrevería a decir que para algunos emprendedores la

falta de ética no sólo es aconsejable, sino necesaria.

No existe ningún tipo de contradicción entre emprendimiento y falta de ética cuando manejamos un concepto de emprendimiento cuyo único objetivo es el incremento ilimitado de la riqueza material y que sitúa el tener por delante del ser en la construcción de un modo personal de ser y estar en el mundo. Un concepto de emprendimiento muy alejado de la filosofía que está detrás de la reflexión de todos aquellos que hemos participado en este número de la Revista Padres y Maestros.

Al acercarnos a la misma pregunta desde un planteamiento humanista vemos, sin embargo, que solamente admite como respuesta un rotundo no. Un no que entiende al emprendedor/a desde una dimensión individual inseparable de su ser social y que integra como parte de su esencia la responsabilidad social que debe acompañar todo proyecto de emprendimiento.

Y es responsabilidad de la familia y la escuela el llevar a cabo este proceso de formación ética desde los primeros años sin esperar a convertirlo en un contenido adquirido de modo paralelo al resto de conocimientos necesarios para iniciar un proyecto de emprendimiento. Porque cuando hablo de siete claves éticas para emprendedores, es necesario insistir en que estoy hablando también de educar la competencia emprendedora desde la condición sine qua non de una formación previa en valores. Nuestro objetivo como educadores no puede ser otro que el de formar personas íntegras que además sean capaces de movilizar su talento en la búsqueda de su pleno desarrollo personal y en la mejora de la sociedad de la que forman parte.

Es cierto que en este camino se hace imprescindible el apoyo activo de las instituciones políticas educativas, impulsando un cambio en el modo de entender lo que significa "formación integral del alumno" y hasta la fecha, ninguno de los sistemas educativos que he conocido en estos veinticinco años de carrera profesional ha apostado realmente por un modelo educativo que equilibre la balanza de las competencias

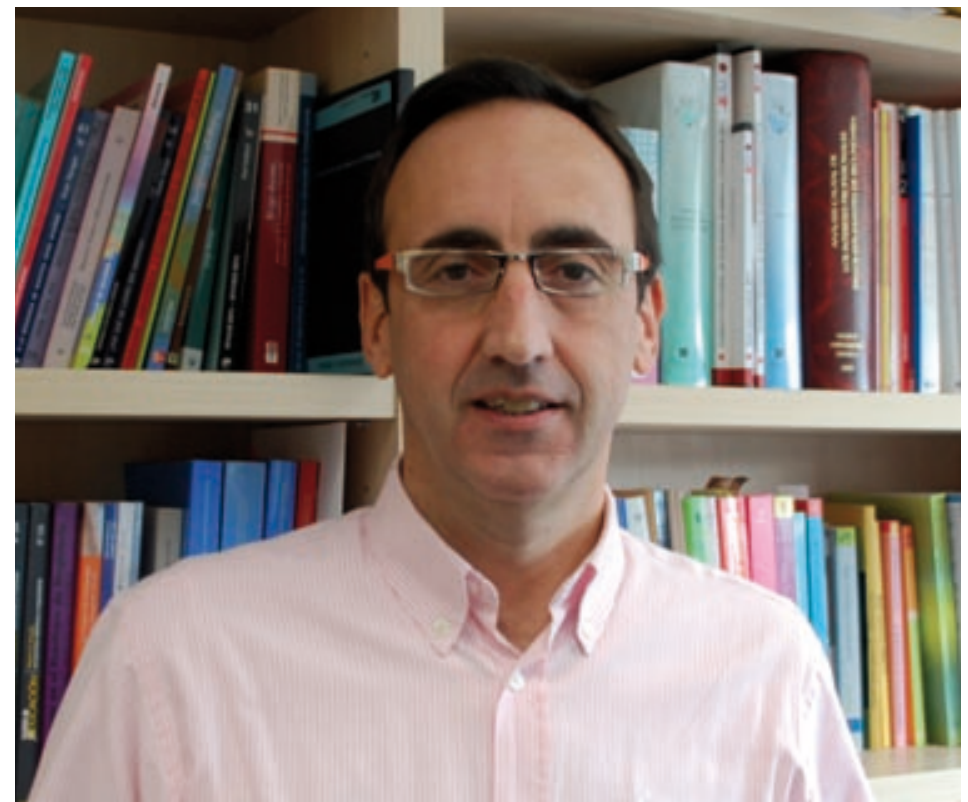

Jerónimo García Ugarte. 
Figura I. FORMACIÓN DE EMPREDEDORES

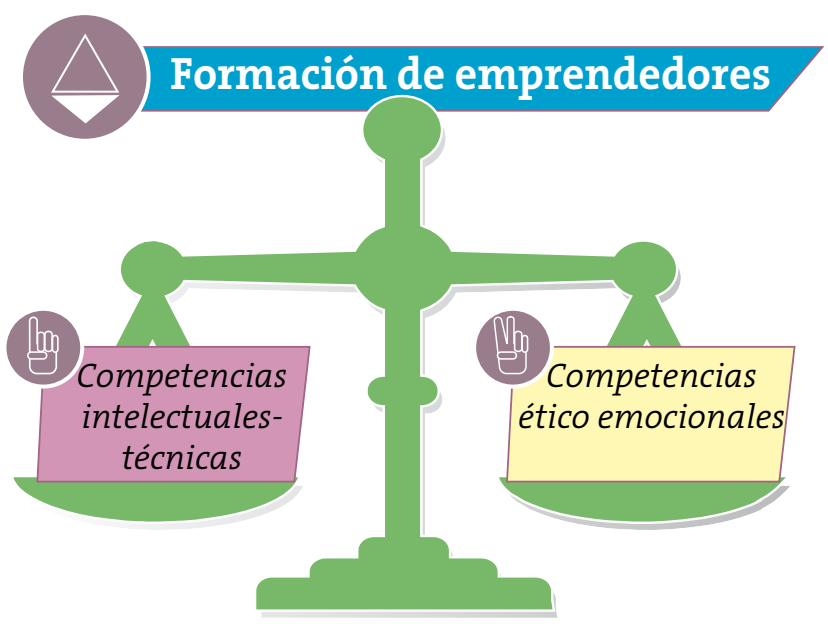

intelectuales y las competencias éticas. Todos, sin excepción, han buscado la formación de buenos profesionales obviando que para ser un buen profesional es absolutamente necesario ser antes una excelente persona (figura I).

El discurso sobre el emprendimiento no puede ceñirse exclusivamente a los estrechos márgenes de la obtención de resultados económicos.

Emprender significa, entre otras cosas, cambio, transformación. Plena actualización de las potencialidades que todos llevamos dentro y que, como miembros de la sociedad, tenemos la responsabilidad de poner al servicio de los demás en la búsqueda conjunta de una sociedad más justa. Lo que excluye, de modo taxativo, cualquier posibilidad de dar por válido cualquier comportamiento que nos aleje de un modo ético de entender lo que significa la palabra emprender.

La ética no es un añadido al hecho de emprender, sino que forma parte de su misma esencia y de ahí la necesidad de que al hablar de educar la competencia emprendedora no olvidemos, en ningún momento, que una parte sustancial de ese proceso educativo debe fijar sus objetivos en una sólida formación en valores. Porque si no, volveremos a caer en la misma realidad a la que ahora miramos asombrados, volveremos a enfrentarnos al hecho de que no todos aquellos que situamos como modelo de emprendimiento construyeron sus proyectos desde cimientos éticos.

Los que sí han sido verdaderos emprendedores son los autores de cuyas citas he partido para reflexionar, brevemente, sobre algunas de estas claves éticas que siempre deben acompañar a un emprendedor. Nada más lejos de mi intención que el tratar de "marcar" estas siete como las únicas y espero que cada uno de los que se acerquen a este artículo aporten en su reflexión alguna de las que, por olvido o falta de espacio, he dejado de mencionar (figura 2).

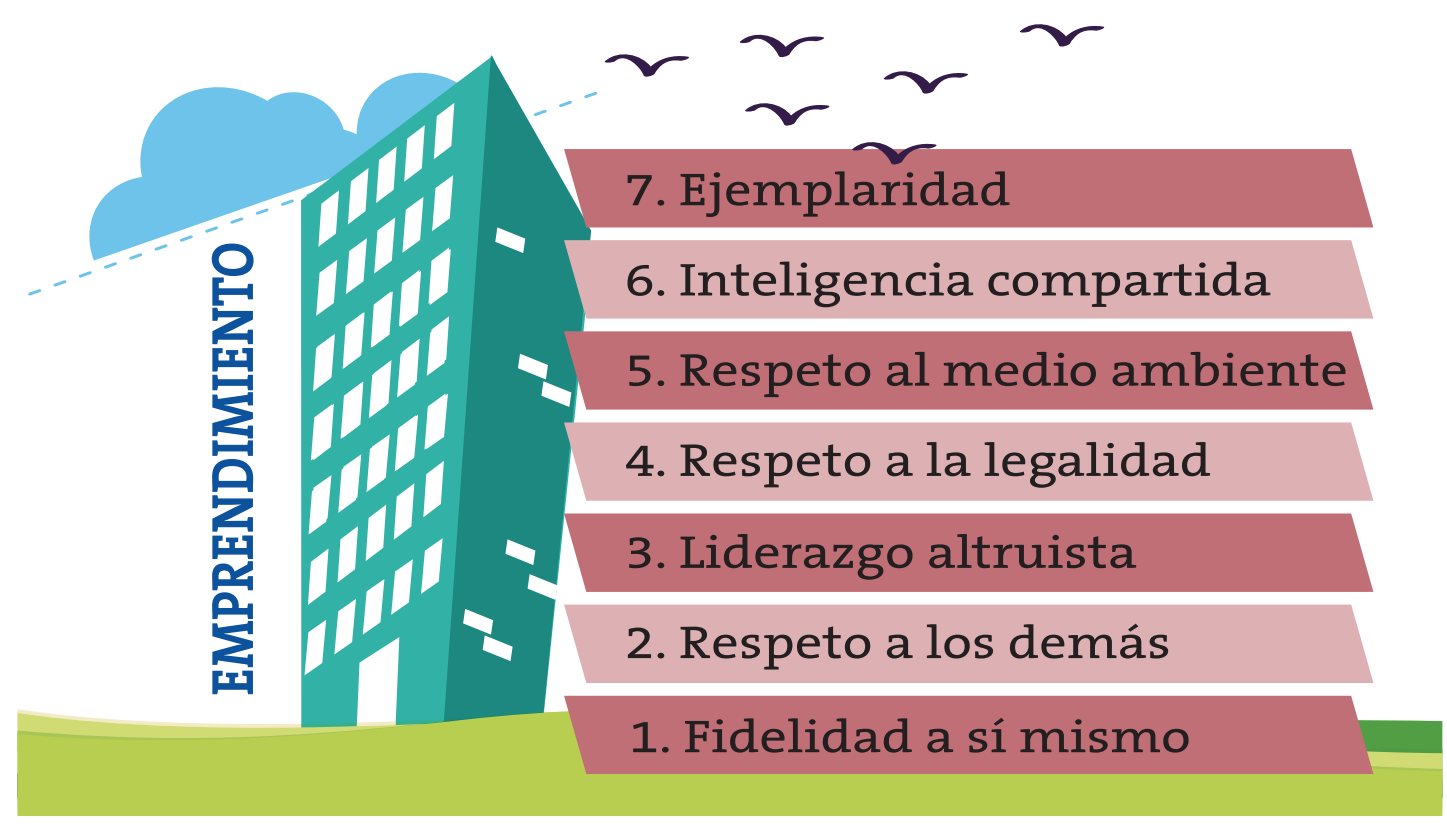




\section{FIDELIDAD A UNO MISMO}

"Una persona es auténtica cuando pone en marcha su voluntad para llevar a cabo su proyecto util”.

ORTEGa y Gasset

El emprendimiento no nace de la imposición sino de la elección. De la libertad de ser lo que queremos ser a partir de aquello que hemos recibido y que forma parte de nuestro bagaje personal y cultural. Construirse como emprendedores es comprometerse con un proyecto vital del que, desde nuestra condición de seres éticos, no podemos sustraernos.

En palabras de Ortega, la autenticidad supone la fidelidad a un proyecto personal que cada uno de nosotros elegimos libremente y no es posible entender el ser emprendedor si no es desde esa fidelidad a uno mismo.

El punto de partida, la primera clave ética de un emprendedor parte, ineludiblemente, de una mirada interior en la que ubicar y encontrar respuesta a la pregunta ipor qué que emprender? Una mirada desde la que diseñar un proyecto personal de vida en el que debe situarse, encontrar "acomodo", todo proyecto de emprendimiento.

En este camino no caben atajos, primero nos construimos como personas integras, fieles a un proyecto personal de vida, fieles a unos principios que cada uno de nosotros hemos elegido y sólo en este marco es posible situar, después, nuestra realidad como emprendedores. Tratar de separar por un lado nuestra propuesta ética y por otra nuestra propuesta de emprendimiento solamente puede conducirnos al fracaso.

\section{Respeto a los demás}

"La igualdad es una necesidad vital del alma humana. La misma cantidad de respeto y de atención se debe a todo ser humano, porque el respeto no tiene grados". SIMONE WEIL

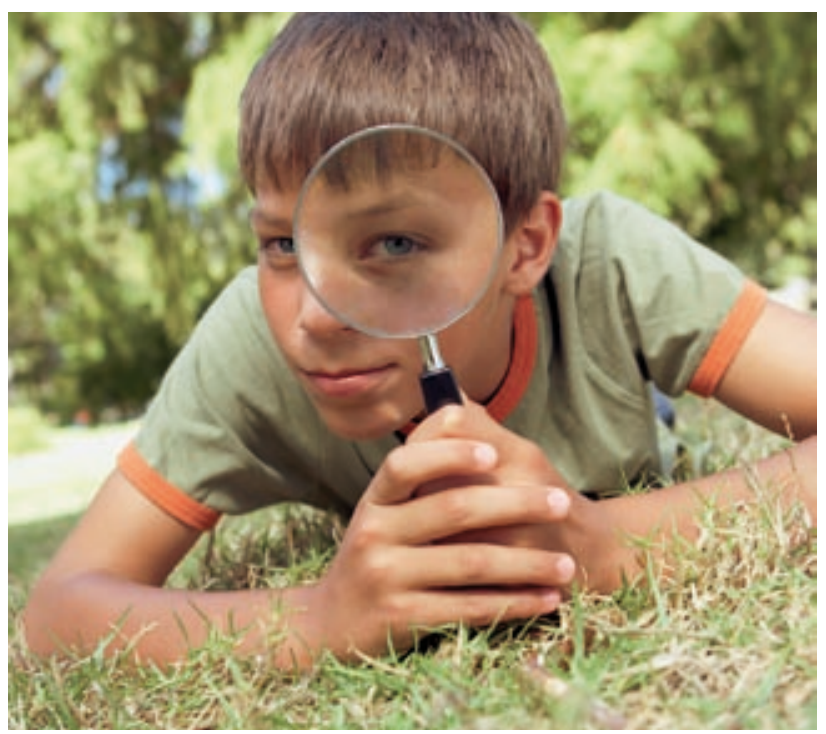

Los emprendedores no son individuos aislados que construyen sus proyectos desde y para su individualidad. Todo emprendedor se relaciona con un entorno formado por personas que, desde distintos ámbitos de colaboración, participan en el mismo proyecto y que merecen todo su respeto.

Una condición inherente al hecho mismo de emprender es, apoyándome en la ética de I. Kant, el tratarse a sí mismo y a los demás siempre como un fin en sí mismos y nunca como un medio.

A la hora de establecer los fundamentos desde lo que vamos a llevar adelante nuestro proyecto de emprendimiento, es necesario no caer en el error de instrumentalizar, cosificar, a los demás y convertirlos en un medio para conseguir nuestros objetivos personales. Porque al hacerlo, vaciamos dicho proyecto del componente ético que le da sentido y validez.

Decíamos anteriormente que nadie nos obliga a emprender, pero a lo que si estamos obligados es a contribuir en la construcción de la mejor sociedad posible cimentada en el respeto a los demás.

\section{Liderazgo. Altruismo Versus egoismo}

"Has venido a la cima de la colina, estás aquí, en el suave promontorio y miras a la otra ladera. Podías empezar a bajar. No es un descenso pronunciado. Podías empezar a bajar, pero la otra ladera conduce al otro valle y allí no has estado nunca".

BELÉN GOPEGUI

Emprender también significa liderar, impulsar y buscar nuevas posibilidades de actuación, nuevas realidades. Un emprendedor debe ser un líder capaz de ir y de llevar a aquellos con los que comparte su proyecto, a un lugar donde no han estado nunca. Ser capaz de transmitir el optimismo necesario para superar miedos e incertidumbres.

Sin menosprecio a otros criterios de clasificación, creo que existen dos modelos fundamentales de liderazgo:

I. El que ejerce un líder que piensa primero en sí mismo y después en su equipo de trabajo.

2. El que ejerce un líder que piensa primero en su equipo y luego en sí mismo.

En el primer caso hablamos de un liderazgo egoísta, mientras que en el segundo lo hacemos de un liderazgo altruista que entiende su realidad emprendedora desde la búsqueda compartida de objetivos personales y sociales. Que entiende que la condición de liderazgo, que forma parte de su misma esencia, le exige priorizar la búsqueda del éxito de los demás como condición para alcanzar el propio.

Me gustaría remarcar que la gran diferencia entre un modelo de emprendimiento-liderazgo egoísta y uno altruista es que el recorrido del primero sólo es posible visualizarlo a corto plazo con fecha segura de caducidad, mientras que en el segundo caso, la perspectiva de futuro se presenta mucho más abierta y 
extensible a tener continuidad en otros proyectos. El primero es un proyecto de pasado y al segundo le espera el futuro.

\section{Respeto a la legalidad}

"Si el hombre fracasa en conciliar la libertad y la justicia, fracasará en todo".

CAmus

Elegir libremente aquello que queremos ser, apostar por un proyecto personal de emprendimiento solamente es entendible dentro del marco que establece la legalidad vigente. La idea de la legalidad como cortapisa de la libertad y la creatividad únicamente puede ser entendida desde el discurso de quien entiende el emprendimiento desde la filosofía maquiavélica del fin justifica los medios...

Sin el respeto a las leyes el emprendedor pierde su condición de tal y acepta como válidos todos aquellos comportamientos que busquen alcanzar sus metas eludiendo los fundamentos de la ética, renunciando, desde ese mismo instante, al amparo que esta misma legalidad le ofrece ante las actuaciones ilegales de los demás.

Hablar de emprendedores y de emprendimiento implica desterrar modos de pensar construidos desde una falsa y superficial filosofía del todo vale... En el discurso del emprendimiento, la libertad y la legalidad no pueden entenderse por separado, forman parte necesaria de una misma realidad.

Si pensamos que una parte importante de las respuestas a los muchos interrogantes, que la crisis actual nos está planteando se encuentran en los emprendedores, no podemos caer en el error de generar una idea de emprendimiento donde lo único que tengamos en cuenta sea el puro logro de objetivos sin importarnos los cimientos ético legales sobre los que se sustentan dichos logros.

\section{actividades de aula}

Proponer a los alumnos un debate sobre: ¿se puede emprender sin ética?

Para el debate elegiremos un moderador y organizaremos la clase en dos grupos que siguiendo el método de discusión pro et contra tendrán que defender la tesis, a favor o en contra, que se les haya asignado.

Para preparar el debate dispondrán de dos o tres días para que puedan recoger información en los medios de comunicación, ejemplos a partir de los cuales poder defender sus opiniones.

Al final del debate se llevará a cabo, entre todos, una recogida de los aspectos más importantes tratados durante el mismo y se extraerán conclusiones.

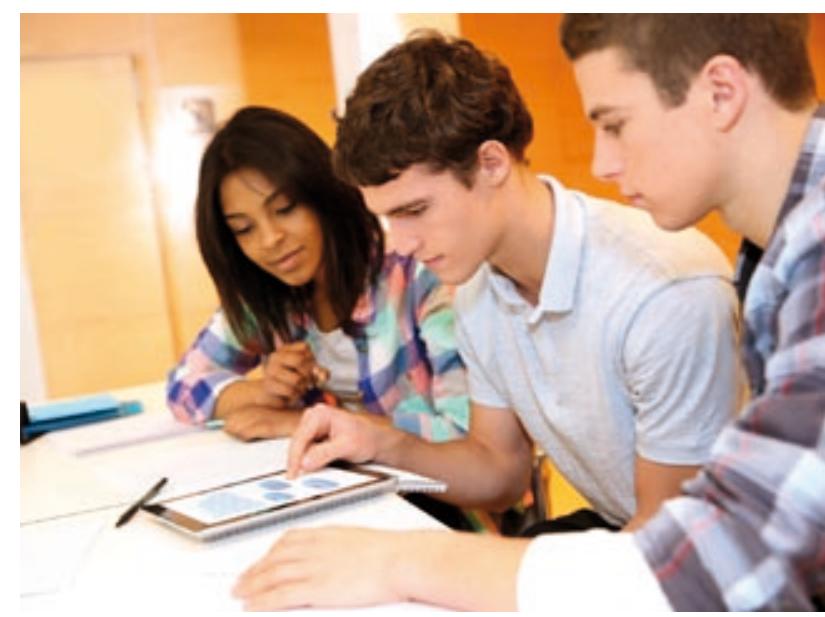

5. Respeto al medio ambiente

"Una sociedad crece bien cuando las personas plantan árboles cuya sombra saben que nunca disfrutarán”.

ProverbIO GRIEGO

En el siglo XVII, el mecanicismo cartesiano nos presentaba la naturaleza como una realidad instrumental puesta al servicio del hombre para su ocupación y explotación. Con el siglo $X X I$ recién iniciado y sin alejarnos de la idea de la naturaleza como el medio en el que y gracias al cual se desarrolla nuestra vida $y$ la del resto de seres vivos, esta forma de mirar se ha trasladado a un plano de igualdad.

Igualdad a la hora de pensar que el respeto que debe acompañar a todo proyecto de emprendimiento no se circunscribe a la relación con los demás, sino a toda aquella realidad que forma parte de nuestro entorno.

Cuando emprendemos en el presente nos proyectamos solidariamente en el futuro porque como dijo Ghandi: "La mejor herencia que podemos dejar a nuestros hijos es amor, conocimiento y un planeta en el que puedan vivir".

Renunciar al respeto al medio ambiente supone volver a mirar al emprendedor desde un plano único de positivismo resultadista, supone renunciar a una mirada humanista a la que no quiero dejar de aferrarme en esta reflexión.

\section{INTELIGENCIA COMPARTIDA}

“La inteligencia evoluciona en conjunto ya que la autonomía individual solamente se puede conseguir a través de un proyecto social, y según la inteligencia de un grupo se pueden mejorar o empeorar los resultados individuales".

J. A. Marina

Buscamos emprendedores que emprendan desde fundamentos éticos y mejor si son eficaces. No trato de establecer ahora, un criterio de selección en función de los resultados obtenidos, pero sí, de sumarme a la idea apuntada en la cita de José Antonio Marina de que somos mucho más eficaces cuando trabajamos, emprendemos, en equipo. 
Cuando encontramos sinergias que aúnan nuestras potencialidades, compensamos nuestras debilidades e incrementamos nuestras fortalezas.

$Y$ esto, que tan bien lo aguanta el papel cuando lo escribo, no siempre es fácil de trasladar a nuestra realidad. No siempre encontramos a nuestra vanidad con las defensas bajas para permitirnos renunciar al uso particular de aquello que sé que me sitúa exitosamente ante los demás.

\section{Cuando encontramos sinergias que aúnan nuestras potencialidades, compensamos nuestras debilidades e incrementamos nuestras fortalezas}

También la inteligencia compartida implica un compromiso ético. El compromiso de poner a disposición de un equipo conocimientos que van a dejar de ser nuestros para pasar a ser de todos, incluso hasta un momento en el que ya lo menos importante sea cuándo y quién aporto algo que él/ella sabía en exclusividad y ahora saben, comparten todos. Un conocimiento que, en el paso de su condición de privado a compartido, va a contribuir al logro de un bien mayor.

\section{EJEMPLARIDAD}

En el mismo momento de estar escribiendo esta reflexión escucho en la radio que España es uno de los países del mundo en los que más ha crecido la corrupción en los últimos años.... Lo que abre ante mí dos posibilidades: no seguir escribiendo el artículo o reafirmarme en la importancia y necesidad de hablar de ética para emprendedores y hacerlo en esta última clave desde la fuerza del ejemplo.

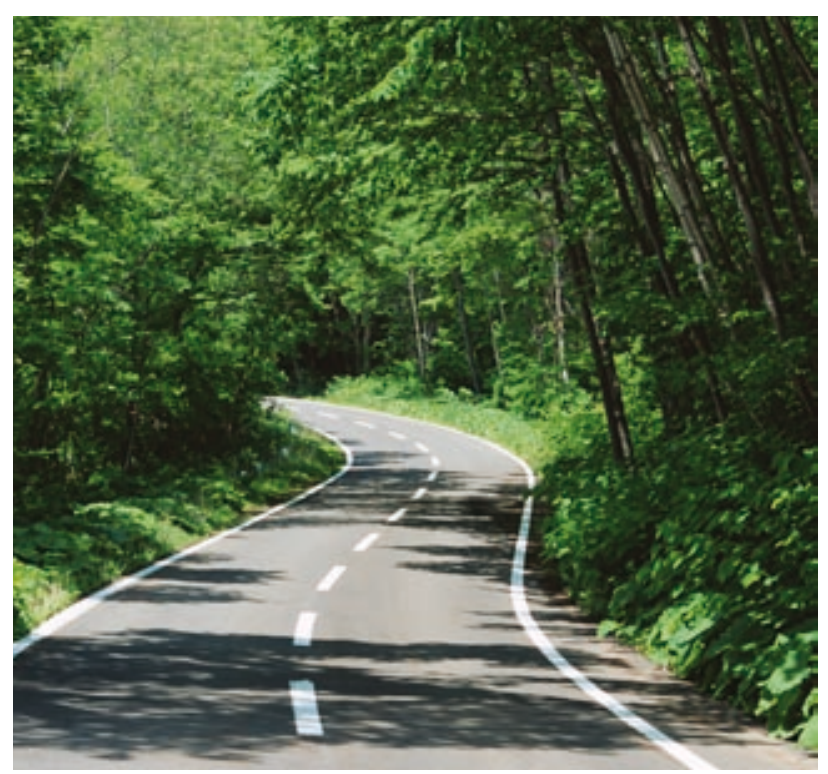

Cuando alguien se convierte en modelo de emprendimiento proyecta, señaliza el camino que en futuro próximo seguirán aquellos a quienes hoy les hablamos con tanto empeño de la necesidad personal y social de convertirse en emprendedores. $Y$ estos adolescentes, jóvenes, no solamente aprenden de aquello que les decimos sino, y cada vez más, de aquello que ven que hacemos.

La fuerza de nuestro discurso se sustenta en la coherencia entre lo que decimos debe ser el modo de pensar y comportarse y lo que cada día ven hacer a aquellos que han apostado por el emprendimiento. Y en este país, y sobre este particular, aún nos queda mucho camino por recorrer.

Y sobre todo, recuperar esa mirada a la educación de la que hablaba al inicio de estas páginas. En contra de los que algunos puedan pensar, nadie deja un día, al azar, de ser ejemplo, lo que realmente ocurre es que nunca aprendió a serlo.

Cada proyecto de emprendimiento levantado al margen de ética, de la legalidad, se convierte en un foco de atención e imitación. Del mismo modo que ocurre al contrario, cada proyecto construido desde las claves éticas que he apuntado a lo largo de estas página se convierte en una fuente de inspiración para aquellos que han aceptado el reto de entender su ser personal y profesional desde su capacidad para emprender.

Siete claves éticas a las que en ningún momento he pretendido dar la suerte de la exclusividad; sino al contrario, abiertas a que todos aquellos que se acerquen a este artículo piensen y añadan las que por omisión, o falta de espacio, también merecen un lugar preferente.

$Y$ qué mejor que terminar recuperando la idea que se erige como columna vertebral de mi reflexión: no podemos hablar de emprendimiento sin hablar de ética y no podemos hablar de ética sin hablar de educación.

\section{Para saber más}

- DitTs, R. (1996). Liderazgo creativo. Barcelona: Ediciones Urano.

- Fernández FernándeZ, J. L. (1994). Ética para empresarios y directivos. Madrid: Esic Editorial.

\section{hemos hablado de:}

Emprendimiento, competencias ético-

emocionales, educación en valores, liderazgo.

Este artículo fue solicitado por PADRES Y MAESTROS en junio de 2013, revisado y aceptado en noviembre de 2013 para su publicación. 